\title{
Septic funiculitis causing systemic disturbances in a Sindi bull
}

Antônio Carlos Lopes Câmara, Igor Louzada Moreira, Gustavo P Braga, Camila Osse de Souza, Lidia dos Santos Pereira, Ernane de Paiva F Novais, Yasmin R Avellar Wendrownik, Cristiane da Silva Pereira", José Renato Junqueira Borges

Hospital Escola de Grandes Animais, Faculdade de Agronomia e Medicina Veterinária, Universidade de Brasília(UnB), Brasília, DF, Brazil

*Corresponding author

e-mail: cristianepereira@unb.br

\section{Abstract}

Septic funiculitis (SF) refers to the chronic infection of the spermatic cord stump where the scrotal incision heal but the stump continues to be infected forming a draining tract. Clinical signs are consider mild and may not appear for weeks and even months after castration. Therefore, this work aimed to report a case of SF causing systemic disturbances in a Sindi bull. The bull was castrated 17 days earlier by a veterinarian using an open technique. After this it presented hyporexia, apathy and weight loss. Clinical evaluation revealed fever $\left(39.8^{\circ} \mathrm{C}\right)$, regular body condition score, reluctance to move, and an inguinal swelling with piosanguinolent discharge. During deep palpation it was impossible to determine the end of the infected spermatic cord and the bull presented severe pain. Hematology revealed leukocytosis $\left(13.2 \times 10^{3} / \mu \mathrm{L}\right)$ by neutrophilia $\left(8.7 \times 10^{3} / \mu \mathrm{L}\right)$ and presence of toxic neutrophils. The bull was diagnosed with SF and possibly sepsis. Antibiotic (enrofloxacin: 5 mg.kg-1 $, \mathrm{IV}, 10$ days) and anti-inflammatory therapy (flunixin meglumine: $2.2 \mathrm{mg} \cdot \mathrm{kg}^{-1}$, IV, 5 days) were promptly started and the bull was prepared for surgery. After sedation (xylazine: 0.2 mg.kg-1 ${ }^{-1}$ ), the bull was induced (ketamine: $2.2 \mathrm{mg} . \mathrm{kg}^{-1}$ and diazepam: $0.025 \mathrm{mg}^{\mathrm{kg}}{ }^{-1}, \mathrm{IV}$ ) and maintained on general anesthesia with isoflurane in a semi closed circuit. This anesthesia choice is explained because of the possible involvement of the inguinal ring and focal peritonitis. Initially, both fistulas were filled with gauze to prevent exudate outflow. After routine pre-operative preparation, a circular incision around each fistula was performed followed by blunt divulsion. Divulsion was deepened until healthy spermatic cord was obtained. Then both cords were ligated using a Reimer emasculator, removing about 25-30 cm of each. Fortunately, there was no involvement of the inguinal ring or peritonitis. A tobacco pouch suture was performed every $5 \mathrm{~cm}$ to reduce dead space with one polyglicolic acid suture. Skin was sutured using one nylon with Wolf pattern. Postoperative care included daily wound cleaning and the above mentioned drugs. 
No complications were observed and the bull made a full recovery. Spermatic cords were longitudinally opened. The right one revealed severe thickening, fibrosis and blood-clotted content with fetid odor, whilst the left one presented also yellow-whitish purulent discharge. SF is a relatively common complication of castration that can occur from extension of scrotal infection or ascendant contamination when using surgical open techniques. In this case, the hypotheses of inadequate antisepsis, use of a contaminated emasculator or ligature and deficient postoperative care by the rancher may have played an important role on the development of SF. Clinical signs are consider mild (pyrexia, lameness, inguinal or scrotal swelling and drainage); but in this bull the infection was severe and promoted systemic disturbances associated with sepsis and/or bacteremia. 